\title{
Assim é, se lhe parece: \\ "em-cena-ação" científica num país fictício em tempos de publicar ou perecer... \\ mas bem que poderia ser no Brasil
}

Murilo Mariano Vilaça ${ }^{1}$ Isabella Lopes Pederneira²

\section{Primeiro ato: A mestranda e a descoberta}

- "E aí, tem publicado?", indaga-se a uma mestranda.

Sem hesitar, ela responde:

- "Não! As revistas não publicam textos de quem não tem doutorado3".

- "Mas e se você convidar a sua orientadora para assinar $o$ artigo ${ }^{4}$ ?", sugere-se a ela.

- "Boa ideia!", ela exclama, como se descobrisse os passos para ascender ao paraíso dantesco.

Programa de Pós-Graduação em Filosofia, Instituto de Filosofia e Ciências Sociais, Universidade Federal do Rio de Janeiro. Largo de São Francisco de Paula, $n^{\circ} 1$, Centro. Rio de Janeiro, RJ, Brasil. 20.051-070. contatoacademico@ hotmail.com ${ }^{2}$ Department of Linguistics, Queen Mary, University of London.

${ }^{3} \mathrm{~A}$ título de exemplo, o periódico Veritas (PUCRS) informa que "A revista publica apenas trabalhos de professores doutores ou em coautoria com doutorandos". Disponível em: <http://

revistaseletronicas.pucrs. br/ojs/index.php/veritas/ about/submissions\# authorGuidelines > Acesso em: 23 jan. 2012.

${ }^{4}$ Órgãos internacionais e nacionais, como a Swiss National Science

Foundation, a Austrian Agency for Scientific Integrity e a Fundação de Amparo à Pesquisa do Estado de São Paulo, têm demonstrado

preocupação com a má conduta definida como "coautoria indevida ou de fachada", citando-a em seus códigos de integridade científica. 


\section{Segundo ato: O doutorando entre a cruz e a espada} ou entre a bolsa e a relevância

- "E aí, tem publicado?", pergunta um doutorando a uma doutoranda.

- "Não. Estou estudando uma nova teoria. Ainda não tenho nada para publicar sobre ela ... estou trabalhando em novas ideias" ", ela responde.

- "Mas você não vai pedir bolsa sanduíche?", ele questiona, pois sabia que ela desejava fazer um estágio em uma universidade no exterior. A verdade é que apenas introduziu a curiosidade para despistar seu verdadeiro objetivo de sondar as publicações da doutoranda. "Você tem de melhorar o seu currículo", afirma, estupefato, o 'realista' doutorando.

- "Ah, eu não vou publicar qualquer coisa apenas para dizer que tenho artigos em revistas", contesta a 'idealista' doutoranda.

- "Sim...", concorda, pensativo, o doutorando, "mas aí você corre o risco de ficar sem a bolsa", conclui, pragmaticamente.

- "Sério? Será que isso é tão determinante assim?", pergunta, demonstrando ligeira preocupação.

- "Acho que não é o único critério, mas um bom currículo ajuda", ele responde.

- "É um absurdo eu ter de publicar qualquer coisa", esbraveja a criteriosa doutoranda. "Eu estou começando a estudar uma teoria e não quero nem posso falar qualquer coisa. Preciso de tempo para produzir ideias, ainda que eu pudesse juntar palavras em frases gramaticais e publicá-las".

A doutoranda deixa o doutorando pensativo, mas a reflexão não é páreo para o pragmatismo produtivista.

\section{Terceiro ato: O doutorando 'produtivo' e o 'improdutivo'}

- "E aí, tem publicado?", inicia-se outra conversa entre doutorandos.

- "Tenho", diz, satisfeito, o 'produtivo'.

- "Eu, não. Tenho tido dificuldades", desabafa o 'improdutivo'.

- "E o pior", constata, sem saída, o 'improdutivo': "lá no meu programa, eu só qualifico se tiver publicado um artigo em revista $B 2$ e só defendo se tiver um em uma revista $B 1^{7 "}$.
${ }^{5}$ Alceu Ferraro,

ex-presidente da ANPEd, afirma que, atualmente,

"ninguém mais tem

tempo para parar e pensar, escrever um artigo tranqüilamente, produzir alguma coisa nova. Tudo é feito em cima do joelho, correndo [...]" (apud Sousa e Bianchetti, 2007, p.402).
${ }^{6}$ Os editores do PLOS Medicine asseveram que, “em alguns países, o financiamento público de instituições inteiras é dependente do número de publicações em periódicos com altos fatores de impacto" (2006, p.707).
${ }^{7}$ De acordo com reportagem de Righetti (2011), Programas de Pós-Graduação têm substituído Teses e Dissertações pela defesa de artigos publicados em periódicos de alto fator de impacto. 


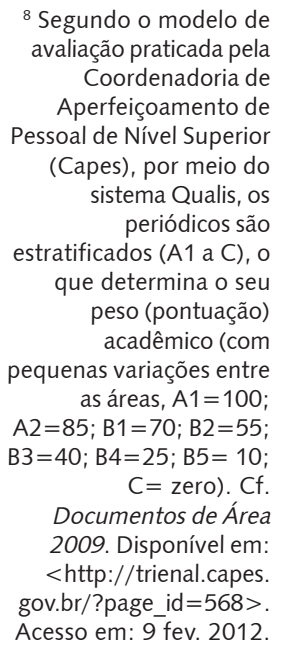

${ }^{9}$ Se $X$ é o número de vezes que os itens citáveis (usualmente, artigos, ensaios, notas, resenhas) de um periódico foram citados em dado período (2010-

2011) em revistas indexadas pelo ISI; e se

Y é o número total

destes itens publicados no mesmo período; o FI

do periódico no ano

subsequente (2012) é igual a $X / Y$.

\section{Quarto ato: O coordenador preocupado}

- "E aí, tem publicado?", pergunta um coordenador de programa de pósgraduação a um dos seus alunos.

- "Sim, professor, graças a Deus", responde, aliviado e orgulhoso.

- "Em que revistas?", desconfia o 'cioso' coordenador.

- "Na ' $x$ ', 'y' e 'z', professor".

O coordenador 'faz as contas' e diz:

- "Bom...continue assim, mas pense em outras revistas, com mais poder de 'produzir diálogo', para escoar a sua produção8".

O aluno sai, e o 'cioso' coordenador volta a ler, ainda mais instigado com os pontos alcançados pelo aluno, o capítulo sobre a construção do $2^{\circ}$ moinho na "Revolução dos Bichos".

\section{Quinto ato: O docente de impacto}

- "E aí, tem publicado?", inicia-se um capcioso diálogo entre pesquisadores de um programa de pós-graduação nota 7.

- "Minha produção está em dia, indo muito bem", orgulha-se um deles.

- "Que bom. Isso é bom tanto para você quanto para o programa", comenta o outro.

- "É ... aquele artigo que enviei para aquela revista de altíssimo fator de impacto foi aceito", comemora o professor.

- "Qual é mesmo o fator de impacto dela?".

- "23,459!", responde orgulhoso.

- "Meus parabéns", congratula-o. "Mas me tire uma dúvida: como esse fator ${ }^{9}$ é precisamente definido?", pergunta.

- "hahaha ... não sei bem, mas o que importa é que a revista tem um alto fator de impacto ... e isso rende muitos pontos no currículo", confessa inescrupulosamente.

- "Acho que envolve número de citações e de artigos, algo assim", tentando ajudar o colega. "Aliás", completa, "acho isso bem relativo". 
- "Como assim?", surpreende-se o orgulhoso autor, pensando na possibilidade de inveja do colega.

- "Não estou desmerecendo a sua 'conquista"', defende-se, "só acho que número de citações não garante a qualidade da revista, menos ainda dos textos nela publicados ${ }^{10}$. Pense comigo, se alguém famoso publica um artigo, provavelmente ele será muito lido e muito citado. Mas um autor pode citar aquele artigo motivado por vários interesses, como 'agregar o valor' da revista e daquele autor famoso ao seu texto, mesmo que seja incapaz de avaliar o que foi pesquisado e publicado. Além disso, como se faz nos casos em que artigos publicados em grandes revistas são denunciados e cancelados por fraude ${ }^{11}$ ? As citações recebidas são canceladas? O fator de impacto é revisto? Enfim...".

- "É, você pode ter alguma razão", comenta o não persuadido 'autor de impacto'.
${ }^{10}$ Críticos, por exemplo, os editores do PLoS Medicine, apontam os limites desse índice de qualidade.

${ }^{11}$ Flores (2005), por exemplo, afirma que um artigo produzido em 1997 e citado 227 vezes foi retirado da Science depois que um dos autores foi considerado culpado em casos de fabricação e falsificação de dados.

\section{Sexto ato: O docente financiável}

- "E aí, tem publicado?", pergunta um pesquisador que quer concorrer a um financiamento de pesquisa com um colega. A sondagem prossegue: "Publicou em alguma A1 internacional, com alto fator de impacto' ${ }^{12}$ ?". Antes que o colega respondesse, ele arrematou o convite: "É que vou concorrer a um edital importante e preciso de pesquisadores com 'bons' currículos para se associarem à pesquisa".

- "Mas de que se trata a pesquisa? Que edital é esse?", interroga.

- "Ah, sim, desculpe-me. Depois te passo os detalhes. Mas não se preocupe, você não vai ter trabalho".

- " Fiquei curioso quanto à possibilidade 'inusitada' de participar de uma pesquisa sem ter trabalho, mas depois a gente conversa melhor", despede-se o desconfiado colega. 
${ }^{13}$ Dowbor (2011), em um texto de rara franqueza, testemunha: "sou obrigado a publicar, pois sem isso o programa da PUC-SP, onde sou professor, não terá pontos necessários ao seu credenciamento" (p.34).

${ }^{14} \mathrm{~A}$ redundância, o plágio e o autoplágio são outras más condutas científicas comuns.

\section{Sétimo ato: $\mathrm{O}$ docente à procura do artigo}

Em um diálogo entre dois docentes renomados que atuam numa pós-graduação 'de excelência', ouve-se:

- "E aí, tem publicado? Já bateu a meta ${ }^{13}$ ?".

O colega responde:

- "Sim, acabei de fechar. E você?".

- "Ainda não. Faltam 'x' pontos. Você não tem um artigo para o qual eu possa 'contribuir'?".

- "Não sei, mas se não tiver, pensamos em algo juntos. O editor da revista ' $x$ ' é meu amigo. Resolveremos isso".

- "Ótimo! É sempre bom escrever contigo", selam a 'camaradagem científica'.

- "Ah, e outra: também podemos 'revisitar' aquele nosso artigo. Um título novo, novas 'visadas' e teremos algo para enviar ${ }^{141}$, sugere perspicazmente.

Um deles parece se recordar da época em que sua mãe falava das cotas que tinha de bater na humilde perfumaria da esquina de um subúrbio, mas não entendeu o porquê. Apenas um ordinário déjà vu...

\section{Oitavo ato: $O$ docente 'sem perfil'}

- "E aí, tem publicado? Seus estudos são interessantes", pergunta e comenta um docente de pós-graduação a um colega.

- "Sim, mas as revistas não estão no Qualis", salienta o colega.

- "Xiiiii...sério? Por que publicou nelas, desperdiçando o texto?", questiona incrédulo. "Eu só publico em revistas B1 para cima".

- "É, acho que serei descredenciado. Colegas já me alertaram para o destino

${ }^{15}$ Idem nota 13. quase inevitáve/5", afirma resignado.

- "É, talvez você não tenha o perfil da pós-graduação mesmo. A graduação te dará mais liberdade para desenvolver as suas ideias", consola o colega. 


\section{Nono ato: A ciência colonizada pela produtividade}

- "E aí, tem publicado?", pergunta uma ciência para outra.

- "Sim, e muito", responde.

- "Ah, então muita coisa tem sido descoberta, muitos problemas têm sido resolvidos, novos conceitos formulados nos seus domínios", conclui aquela.

- "É...digamos que sim...mas que nenhuma concorrente nos ouça, vejo muito ${ }^{16}$ Idem nota 14. 'mais do mesmo"16, muito barulho para pouca novidade, muitas verdades reconfirmadas com outras palavras, algumas falsidades também".

- "É mesmo", compartilha a ciência amiga. "Mas esse assunto é delicado. Melhor nem tocar nele. Afinal, essa é a regra: produzir é a alma do negócio. E de muita quantidade acaba saindo alguma coisa boa".

- "Quem sabe ... vamos torcer", afirma ceticamente.

\section{Uma história sem moral}

A cansativa insistência na questão "E aí, tem publicado?" não é apenas um recurso estilístico ou retórico. No nosso entendimento, ela revela traços da cultura acadêmico-científica contemporânea. Como um modo corriqueiro de iniciar conversas e regular condutas no meio acadêmico, ela exprime uma tendência traduzível por uma série de aforismos (publish or perish - publicar ou perecer - e pressure to publish - pressão para publicar - são os mais famosos) que, neste texto, são representados nos discursos construídos.

As cenas têm inspiração pirandelliana, imersas no labirinto das aparências e nas farsas cotidianas. "Assim é, se lhe parece" é a tradução de uma peça de Pirandello: "Così è (se vi pare)". Nela, a verdade é teatralmente abordada nos contextos da realidade e da aparência. As personas que usamos misturam aparência e realidade acadêmico-científica. Concernem às máscaras da realidade oficialmente instituída, expressando algo que predomina, sem, contudo, excluir outras formas de em-cena-ação.

Sem mocinhos ou bandidos, finais felizes ou trágicos, as personagens convergem para um ponto comum. A produtividade parece conjugar interesses; forjar círculos virtuosos ou viciosos; representando um ideal de realidade científica tangível, sobretudo numericamente. "É evidente", diz-se, "a ciência brasileira avança ... já é a sexta colocada em produtividade no mundo".

Resta, todavia, problematizar a ditadura da constatação numérica, criticando e questionando seus fundamentos e efeitos. O conhecimento deve ser qualificado por onde é publicado? A ditadura do periódico é justa ou correta? O que o publicar ou perecer já gera em termos de más condutas científicas? Quais os efeitos mediatos da cientometria vigente?

Cenas do próximo capítulo, esperando novas em-cena-ações no teatro acadêmico-científico. 


\section{"Roteiristas associados"}

\section{AUSTRIAN AGENCY FOR SCIENTIFIC INTEGRITY. Rules of procedure of the}

Commission for Research Integrity: guidelines for the investigation of alleged scientific misconduct (Annex I). Disponível em: <http://www.oeawi.at/downloads/ Richtlinien_zur_Untersuchung_von_Vorwuerfen_wissenschaftlichen_Fehlverhaltens_e.pdf $>$. Acesso em: 9 fev. 2012.

COORDENADORIA DE APERFEIÇOAMENTO DE PESSOAL DE NÍVEL SUPERIOR CAPES. Avaliação Trienal 2007-2009. Documentos de Área, 2009. Disponível em: <http://trienal.capes.gov.br/?page_id=568>. Acesso em: 9 fev. 2012.

DOWBOR, L. O professor e a propriedade intelectual. Disponível em: <http:// dowbor.org/2011/08/o-professor-frente-a-propriedade-intelectual-7.html/>. Acesso em: 05 mar. 2013.

FLORES, G. Science retracts highly cited paper. GenomeBiology, v.6, n.6, 2005. Disponível em: <http://genomebiology.com/2005/6/6/spotlight-20050617-01>. Acesso em: 23 jan. 2012.

FUNDAÇÃO DE AMPARO À PESQUISA DO ESTADO DE SÃO PAULO - FAPESP. Código de boas práticas científicas. 2011. Disponível em: <http://www.fapesp.br/ boaspraticas/codigo_fapesp0911.pdf>. Acesso em: 9 fev. 2012.

RIGUETTI, S. A vez dos artigos. Obs. Impr., v.15, n.655, 2011. Disponível em: <http://www.observatoriodaimprensa.com.br/news/view/a_vez_dos_artigos>. Acesso em: 9 fev. 2012.

SOUSA, S.Z. ; BIANCHETTI, L. Pós-graduação e pesquisa em educação no Brasil: o protagonismo da ANPEd. Rev. Bras. Educ., v.12, n.36, p.389-409, 2007. Disponível em: <http://www.scielo.br/pdf/rbedu/v12n36/a02v1236.pdf>. Acesso em: 9 fev. 2012.

SWISS NATIONAL SCIENCE FOUNDATION. Regulations of the National Research Council on the treatment of scientific misconduct by applicants and grantees. 2009. Disponível em: <http://www.snf.ch/SiteCollectionDocuments/ ueb_org_fehlverh_gesuchstellende_e.pdf>. Acesso em: 23 jan. 2012.

THE PLOS MEDICINE EDITORS. The impact factor game: it is time to find a better way to assess the scientific literature (Editorial). PLoS Medicine, v.3, n.6, p.707-8, 2006. Disponível em: <http://www.plosmedicine.org/article/info:doi/10.1371/ journal.pmed.0030291>. Acesso em: 9 fev. 2012.

VERITAS. Revista de Filosofia da PUC-RS. Diretrizes para os autores. Disponível em: $<$ http://revistaseletronicas.pucrs.br/ojs/index.php/veritas/about/ submissions\#authorGuidelines >. Acesso em: 23 jan. 2012. 